\title{
The next generation Antarctic digital magnetic anomaly map
}

\author{
R. R. B. von Frese, ${ }^{1,2}$ A. V. Golynsky, ${ }^{3}$ H. R. Kim, ${ }^{4}$ L. Gaya-Piqué, ${ }^{5}$ E. Thébault, ${ }^{5}$ M. Chiappini, ${ }^{6}$ \\ M. Ghidella, ${ }^{7}$ A. Grunow, ${ }^{2}$ and the ADMAP Working Group \\ ${ }^{1}$ School of Earth Sciences, The Ohio State University, Columbus, OH 43210, USA (vonfrese@osu.edu) \\ ${ }^{2}$ Byrd Polar Research Center, The Ohio State University, Columbus, OH 43210, USA (grunow.1@osu.edu) \\ ${ }^{3}$ VNIIOkeangeologia, 1, Angliysky Ave., St. Petersburg, 190121, Russia (sasha@vniio.nw.ru) \\ ${ }^{4}$ UMBC/GEST at NASA/GSFC, Planetary Geodynamics Lab, Code 698, Greenbelt, MD 20771, USA (kimhr@core2.gsfc.nasa.gov) \\ ${ }^{5}$ Equipe de Géomagnétisme, Institut de Physique du Globe de Paris - CNRS, 4 place Jussieu, 75252 Paris Cedex 05, France (gaya@ipgp.jussieu.fr) \\ ${ }^{6}$ Istituto Nazionale di Geofisica e Vulcanologia, Via di Vigna Murata 605, 00143 Roma, Italy (chiappini@ingv.it) \\ ${ }^{7}$ Instituto Antártico Argentino, Cerrito 1248, (1010) Buenos Aires, Argentina (mghidella@dna.gov.ar)
}

\begin{abstract}
Initiated in 1995, the Antarctic Digital Magnetic Anomaly Project (ADMAP) produced the first magnetic anomaly map of the Antarctic region south of $60^{\circ} \mathrm{S}$ (Golynsky et al., 2001). This map synthesized over 7.1 million line$\mathrm{kms}$ of survey data available up through 1999 from marine, airborne and Magsat satellite observations. Since the production of the initial map, a large number of new marine and airborne surveys and improved magnetic observations from the Ørsted and CHAMP satellite missions have become available. In addition, an improved core field model for the Antarctic has been developed to better isolate crustal anomalies in these data. The next generation compilation also will likely represent the magnetic survey observations of the region in terms of a high-resolution spherical cap harmonic model. In this paper, we review the progress and problems of developing an improved magnetic anomaly map to facilitate studies of the Antarctic crustal magnetic field.
\end{abstract}

Citation: von Frese, R.R.B., et al. (2007), The next generation Antarctic Digital Magnetic Anomaly Map (ADMAP), in Antarctica: A Keystone in a Changing World - Online Proceedings of the $10^{\text {th }}$ ISAES, edited by A.K. Cooper and C.R. Raymond et al., USGS Open-File Report 2007-1047, Short Research Paper 093, 4 p.; doi:10.3133/of2007-1047.srp093

\section{Introduction}

Since the 1957/58 IGY, the international community has expended considerable effort and resources on magnetic surveying to investigate the crustal properties of the Antarctic. The Antarctic Digital Magnetic Anomaly Project (ADMAP) was initiated in 1995 to conserve these data for future studies and to enhance their geological utility by compiling them into a regional map (Chiappini et al., 1998). The first magnetic anomaly map of the Antarctic combined over 1.5 million line-kilometers of marine and aeromagnetic survey data up through 1999 with more than 5.6 million line-kilometers of Magsat satellite magnetic observations (Golynsky et al., 2001). The $5-\mathrm{km}$ grid of this map is available at www.earthsciences.osu.edu/admap, and the DVD of the survey data in the compilation is nearly ready for release to the World Data Centers. Furthermore, the US Polar Rock Repository (www-bprc.mps.ohiostate.edu/emuwebusprr) maintains compilations of Antarctic rock magnetic and other physical properties that support geological applications of the ADMAP database. Numerous publications including special issues of two scientific journals (Chiappini \& von Frese, 1999; von Frese et al., 2002) highlight the geological utility of the ADMAP compilation.

To help fill in the coverage gaps between the nearsurface surveys, which are particularly extensive in East Antarctica, we used the satellite magnetic observations from the 400-km altitude, 6-month Magsat mission. However, these satellite data were collected during austral summer and fall periods, and thus are maximally corrupted by external magnetic field variations. Much cleaner Antarctic satellite magnetic observations from several austral winters are now available from the Ørsted and CHAMP missions at altitudes of about 600 and 400 $\mathrm{km}$, respectively. The measurement accuracies of these observations are also better than Magsat's by roughly an order of magnitude.

To obtain effective estimates of near-surface anomalies in the coverage gap, we optimized the inversion of the satellite data to match the near-surface anomaly observations around the gap's perimeter (Kim et al., 2004; 2007). Simulations suggest that the use of these new satellite data improves the gap estimates by nearly $75 \%$ relative to the Magsat predictions. Plate 1 gives the improved ADMAP map with the Magsat-based gap predictions replaced by the predictions from the Ørsted and CHAMP observations. Limited comparisons with data from new surveys conducted since 1999 in Figure 1 shows that the gap predictions and near-surface observations are regionally consistent (Kim et al., 2007).

The next generation ADMAP map will also benefit considerably from the Antarctic Reference Model (ARM; Gaya-Piqué et al., 2006), which is an improved core field model for extracting crustal components in the survey data. This spherical cap harmonic model honors the spatial and temporal properties of the Antarctic core field as recorded over the period 1960-2002 by an international network of 28 observatories and satellite magnetic data from six missions. The ARM predictions have greater sensitivity for the Antarctic spatial and temporal variations of the core field than conventional global spherical harmonic geomagnetic field models like the IGRF-10 (IAGA, 2005).

Tests on the Arctowski, Scott Base, Syowa, and Vostok geomagnetic observatory data through 2003, for 
example, show that the ARM estimates of the annual variations of Antarctic core field are roughly $31 \%$ and $22 \%$ better than the IGRF-10 and CM4 (Sabaka et al., 2006) estimates, respectively. We also checked the core field predictions at the Georg von Neumayer (GVN) observatory, which these models did not include. The GVN observatory operated over the period 1983.5-1991.5 on the coast of Dronning Maud Land $\left(70.617^{\circ} \mathrm{S}\right.$, $\left.351.633^{\circ} \mathrm{E}\right)$. We found that the ARM estimates of the field at this observatory were $76 \%$ and $75 \%$ better than the respective IGRF-10 and CM4 estimates. Additionally, ARM estimated the mean secular variation some $78 \%$ and $75 \%$ better than the respective IGRF-9 and CM4 models.

These comparisons only considered the CM4 coefficients up to the conventional degree 13 characterization of the main field and we did not investigate possible advantages of higher degree models. The comparions also ignored any effects of external field contributions in the observatory annual means. However, we are studying these issues as part of our efforts to improve the reduction of Antarctic survey data to enhance their crustal components.

The new updated versions of ARM will allow the next generation ADMAP crustal anomaly compilation to take maximum advantage of the Antarctic geomagnetic observatory data from the present back to the 1957/58 IGY. Furthermore, considerable improvement of the satellite-altitude Antarctic crustal anomaly estimates will result from ESA's low-Earth-orbiting SWARM mission that is scheduled for launch in 2010. SWARM will include two satellites orbiting in tandem that will allow us to map the horizontal gradients of the geomagnetic field with minimal effects from the strong, transient south polar external fields. Thus, SWARM will enable us to estimate the regional crustal anomaly field of the Antarctic with minimal ambiguity.

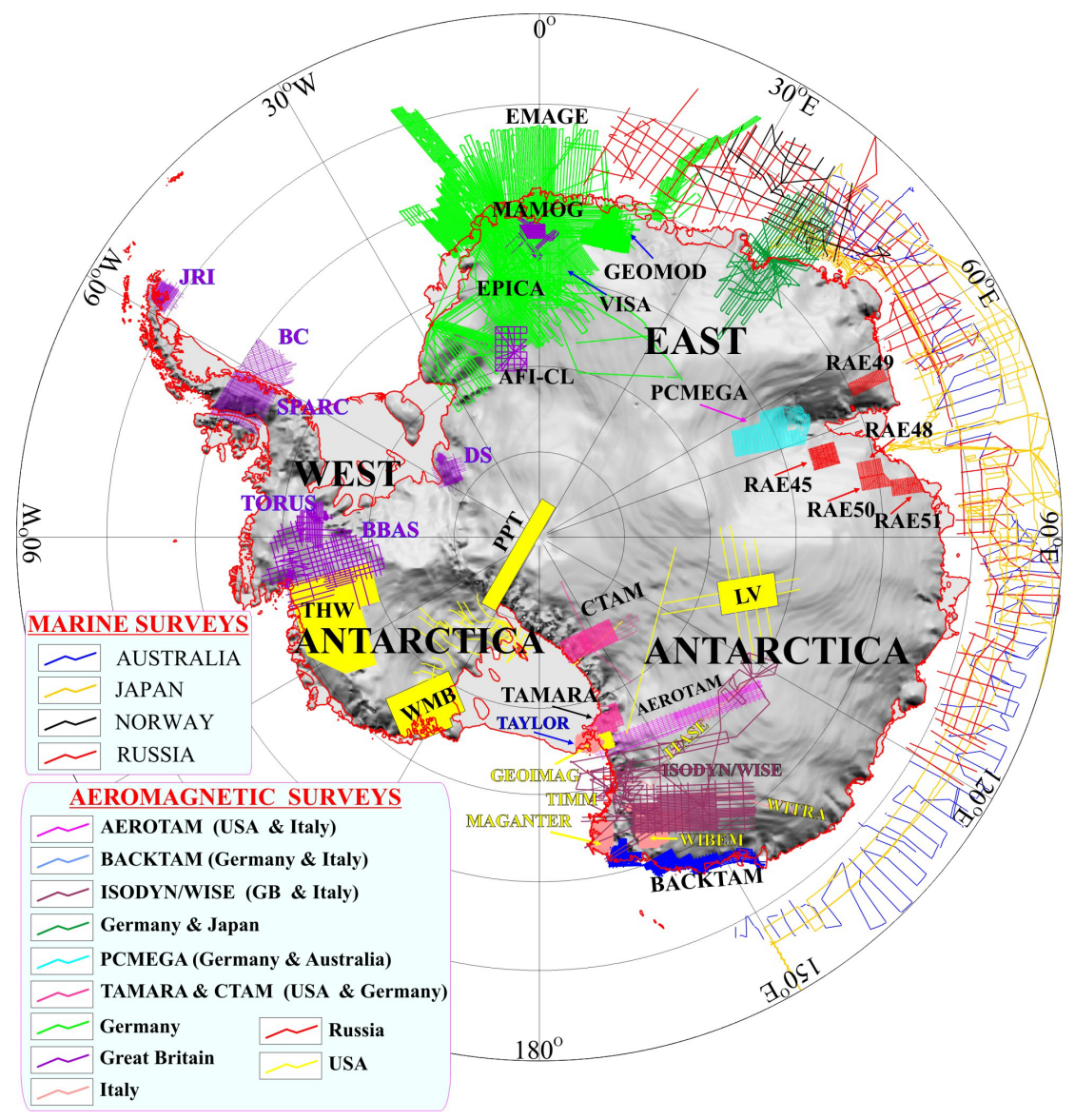

Figure 1. Survey tracks for the roughly one million line-kilometers of new marine and aeromagnetic data that await capture by the ADMAP database.

\section{Discussion}

The need for updating the ADMAP map is evident from the roughly one million line-kilometers of new nearsurface survey data in Figure 1. Clearly, the Antarctic geomagnetics' community remains very active in crustal anomaly mapping. These new surveys involve members of ADMAP who operate under protocols that seek to archive the data in the ADMAP database within 6 years of completing the field survey efforts. However, given the prodigious number of new surveys, our data archival 
efforts are becoming too extensive and complex to handle on the informal basis that we have been conducting them to date. Thus, we are working to acquire the services of a dedicated ADMAP data manager to monitor new survey activities and integrate the survey data into ADMAP's database as they become available. The data manager also is necessary to extract data from the international archives of the working group's members who represent some 12 countries with Antarctic programs.

We are also working to develop a more analytically useful format than the simple grid for representing the map. In particular, we are investigating the use of spherical cap harmonics for modeling the data at the 10$\mathrm{km}$ Nyquist wavelength of the database. The cap model will allow investigators to estimate the magnetic anomalies and their gradient and tensor components anywhere on and above the Antarctic surface, and thus will greatly expand the geological utility of the database.

Figure 2 shows our initial results in developing a high-degree cap model for the ADMAP database. The map gives spherical cap anomaly estimates for the $30^{\circ}$ radius cap centered on the South Pole. The cap model was computed to degree $\mathrm{K}=120$ that corresponds to the minimum wavelength of $111 \mathrm{~km}$. The correlation coefficient of fit to the observed anomalies is 0.85 with standard and mean deviations of the differences of 43 and $42 \mathrm{nT}$, respectively. These results are encouraging for the high-degree modeling of the anomalies and their components in the ADMAP database. The newly revised spherical cap modeling proposed by Thébault et al. (2006) will allow us to represent subsets of the database in full detail that we can combine into a grand highresolution model of the ADMAP database.

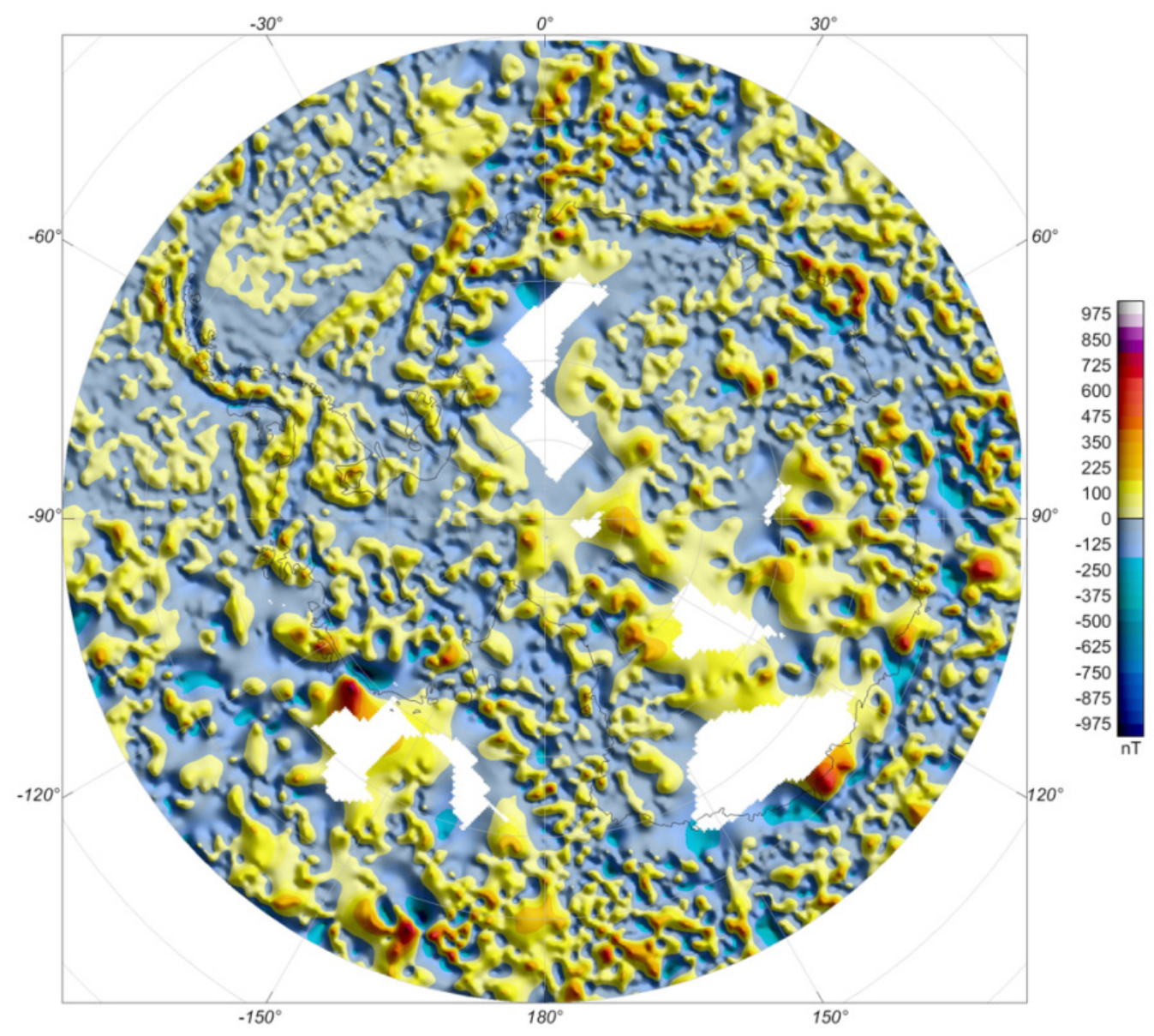

Figure 2. Spherical cap harmonic model at the wavelength resolution of $111 \mathrm{~km}$ for the near-surface ADMAP data with simulated coverage gaps (white areas).

Given the substantial increase in the size of the magnetic database and the advances achieved for estimating and representing the crustal anomaly data, momentum is quickly building for an improved crustal anomaly map to aid Antarctic geological studies. Thus,
ADMAP is working to obtain support for producing the next generation map, although the Italian, US, and other national Antarctic research programs are already allocating resources to the initiative. 


\section{Conclusions}

Considerable progress has been made for the development of the next generation ADMAP map. The amount of near-surface magnetic survey data has nearly doubled, and effective procedures are now available for using state-of-the-art satellite magnetic observations to estimate near-surface anomaly values in the coverage gaps of the airborne and marine surveys. In addition, an improved core field model for the Antarctic was developed to enhance the reduction of survey observations for their crustal anomaly components. The production of a high-degree spherical cap harmonic model of the database also has significant potential for enhancing the geological utility of the ADMAP compilation. Thus, with the imminent release of the survey data that went into the initial map and momentum building for the next generation map, ADMAP is poised to make substantial contributions to the present IPY.

Acknowledgments. We thank SCAR for supporting the activities of the ADMAP expert group. The U.S. National Science Foundation under grant NSF-OPP 0338005 also supported aspects of this study.

\section{References}

Chiappini, M., and R.R.B. von Frese, (1999), Advances in Antarctic Geomagnetism, Annali di Geofisica, 42, 141-351.

Chiappini, M., R.R.B. von Frese, and J.K. Ferris, (1998), Effort to develop magnetic anomaly database aids Antarctic research, Eos, Trans. AGU, 79, 290-291.

Gaya-Piqué, L.R., D. Ravat, A. de Santis, and J.M. Torta, (2006), New model alternatives for improving the representation of the core magnetic field of Antarctica. Antarctic Sci. 18, 101-109.

Golynsky, A., M. Chiappini, D. Damaske, F. Ferraccioli, J. Ferris, C. Finn, M. Ghidella, T. Ishihara, A. Johnson, H.R. Kim, L. Kovacs, J. LaBrecque, V. Masolov, Y. Nogi, M. Purucker, P. Taylor, and M. Torta, (2001), "ADMAP - Magnetic Anomaly Map of the Antarctic," 1:10 000000 scale map, in Morris, P., and R. von Frese, eds., BAS (Misc.) 10, Cambridge, British Antarctic Survey.

International Association of Geomagnetism and Aeronomy (IAGA), Division V, Working Group V, (2005), The 10th generation international geomagnetic reference field. Geophys. J. Int., 161, 561565 .

Kim, H.R., R.R.B. von Frese, Golynsky, A.V., P.T. Taylor, and J.W. Kim, (2004), Applications of satellite magnetic observations for estimating near-surface magnetic anomalies, Earth, Planets, and Space, 52, 955-966.

Kim, H.R., R.R.B. von Frese, P.T. Taylor, A.V. Golynsky, L.R. GayaPiqué, and F. Ferraccioli, (2007), Improved magnetic anomalies of the Antarctic lithosphere, submitted to Geophys. J. Int. doi.10.1111/j.1365-246X.2007.03516x.

Sabaka, T. J., N. Olsen, and M. Purucker, (2004), Extending comprehensive models of the Earth's magnetic field with Ørsted and CHAMP data, Geophys. J. Int., 159, 521-547.

Thébault, E., J.J. Schott, and M. Mandea, (2006), Revised spherical cap harmonic analysis (R-SCHA): validation and properties, J. Geophys. Res., 111, B01102, doi:10.1029/2005JB003836.

von Frese, R.R.B., P.T. Taylor, and M. Chiappini (ed.s), (2002), Magnetic Anomalies of the Antarctic, Tectonophysics, 247, 1-187. 